\title{
ANALISIS SOSOK LAISA DENGAN KAJIAN SEMIOTIK FERDINAND DE SAUSSURE PADA NOVEL DIA ADALAH KAKAKKU KARYA TERE LIYE
}

\author{
Daniati $^{1}$, Ari Musdolifah ${ }^{2}$, Kiftian Hady $\mathbf{P}^{3}$ \\ Universitas Balikpapan ${ }^{1}$, Universitas Balikpapan ${ }^{2}$, Universitas Balikpapan ${ }^{3}$ \\ pos-el: daniaty130@gmail.com ${ }^{1}$, ary.musdolifah@uniba-bpn.ac.id ${ }^{2}$, kiftian@uniba-bpn.ac.id ${ }^{3}$
}

\begin{abstract}
ABSTRAK
Penelitian ini dilatarbelakangi cerita novel karya Tere Liye yang mengandung nilai-nilai religius, sosial, moral dan juga estetika. Tere Liye sering menggunakan kata-kata yang ringan, mudah dimengerti dan terkadang menggelitik pada karyanya, selain itu menggunakan alur cerita dan bahasa yang mudah dipahami, serta bahasa kiasan yang indah. Tujuan dalam penelitian ini adalah untuk mendeskripsikan analisis sosok Laisa dengan kajian semiotik Ferdinand De Saussure pada novel Dia Adalah Kakakku karya Tere Lieye. Penelitian ini menggunakan metode deskriptif dan jenis penelitian kualitatif. Teknik analisis data dalam penelitian ini menggunakan teknik analisis simak dan catat. Hasil penelitian ini menunjukkan bahwa ditemukan 33 tanda yang berhubungan dengan sosok Laisa. 5 tanda sosok baik hati, 11 tanda sosok rela berkorban, 8 tanda sosok kasih sayang, 1 tanda sosok mandiri, e tanda sosok kuat dan 4 tanda sosok sabar.
\end{abstract}

Kata kunci : Semiotik, Novel, Tanda, Penanda, Petanda.

\section{ABSTRACT}

This research is motivated by a novel by Tere Liye that contains religious, social, moral and aesthetic values. Tere Liye often uses light, easy to understand and sometimes tickling words in his work, besides using story lines and language that is easy to understand, as well as beautiful figurative language. The purpose of this research is to describe the analysis of Laisa's figure with Ferdinand De Saussure's semiotic study on the novel He Is My Brother by Tere Lieye. This research uses descriptive methods and qualitative research types. Data analysis techniques in this study used the analysis and note taking techniques. The results of this study indicate that found 33 signs associated with the figure of Laisa. 5 signs of benevolent figures, 11 signs of willing sacrifice, 8 signs of affection, 1 signs of independent figures, e signs of strong figures and 4 signs of patient figures.

\section{Keywords: Semiotics, Novels, Sign,Signifer, Signified.}

\section{PENDAhULUAN}

Karya sastra lahir dari sebuah imajinasi yang diekspresikan seorang pengarang. Pengarang berusaha menyampaikan pengalaman, perasaan, ide, dan semangatnya melalui karya sastra yang diciptakan agar pembaca dapat memahami dan mengapresiasi apa yang disampaikannya. Karya sastra yang mudah dipahami dan digemari adalah prosa yang biasa disebut fiksi. Fiksi dikenal dengan kisah khayalan, imajinatif, bersifat rekaan yang bertujuan memberikan hiburan. Nurgiyantoro (Maslikatin, Mariyati, \& Armis, 2015, pp. 1-2).

Novel merupakan bagian dari genre prosa fiksi. Berkaitan dengan pengertian novel sebagai karya sastra berbentuk prosa fiksi. Novel termasuk fiksi (fiction) karena novel merupakan hasil khayalan atau sesuatu yang sebenarnya tidak ada. novel merupakan sebuah karya sastra prosa fiksi yang isinya pas, tidak berlebih dan mengandung unsur-unsur cerita, tokoh, alur, latar rekaan yang 
mengisahkan kehidupan atas dasar sudut pandang dan mengandung nilai hidup, dan diceritakan mengenai kehidupan para tokoh secara mendetail untuk memudah kan para pembaca dalam memahaminya.

Salah satu novel berjudul Dia Adalah Kakakku merupakan salah satu novel karya sastra prosa fiksi yang menarik untuk dibaca dan dibahas. Selain menarik untuk dibaca dan dibahas, novel ini juga dapat diamati berdasarkan tanda yaitu berupa penanda dan petanda. Tanda-tanda yang akan diteliti yaitu penanda dan petanda yang terdapat pada novel Tere Liye.

Penelitian ini membahas mengenai sosok kak Laisa yang terkandung dalam sebuah novel karya Tere Liye yang berjudul Dia Adalah Kakakku yang menarik untuk dibahas karena dalam novel ini menceritakan tentang seorang kakak yang mengorbankan apapun agar adik-adiknya bisa bersekolah. Menceritakan tentang rasa sabar, penerimaan dan perjuangan Selain itu, dalam novel tersebut terdapat tanda-tanda lain yang mendukung kata-kata untuk diteliti.

Mengenai tanda akan mengarahkan kita kepada ilmu yang mempelajari tentang tanda itu sendiri, yaitu semiotik. Semiotik adalah ilmu yang dapat digunakan untuk mengkaji sebuah tandatanda di dalam karya sastra. (Berger, 2015, p. 8) mengemukakan semiotik adalah ilmu yang mengkaji tentang penanda dan yang di tandai (konsep), kode, ikon-ikon, dan indeks-indeks.

Novel merupakan karya sastra yang mengandung tanda yang dapat diteliti, salah satu contoh karya sastra tersebut adalah novel Tere Liye yang berjudul Dia Adalah Kakakku dan novel tersebut dapat dianalisis menggunakan semiotik untuk mengamati tanda-tanda yang terdapat di dalam novel tersebut.

Berdasarkan hal tersebut peneliti mengkaji hubungan antara penanda dan pertanda sebagai acuan untuk mendeskripsikan suatu makna pada nove
Dia Adalah Kakakku karya Tere Lieye. Yang mana pada novel tersebut peneliti akan memfokuskan penelitian pada Laisa, yaitu sosok Laisa yang terdapat pada novel tersebut. Penanda adalah acuan dari pemerolehan suatu tandadalam semiotik. Penanda merupakan suatu bahan yang menandakan. Signifier (penanda) merupakan elemen fisik dari sebuah tanda yang meliputi tanda, kata-kata, imager dan suara. Saussure mengatakan Signifier (penanda) bunyi yang bermakna atau coretan yang bermakna. Contoh penanda, gambar rambu-rambu lalu lintas "P" yang disilang adalah penanda yang diperoleh dari sebuah elemen fisik dari tanda itu sendiri. Petanda adalah acuan kedua dari pemerolehan suatu tanda dalam semiotik. Petanda merupakan suatu konsep mutlak yang didapat pada tanda fisik yang ada. Konsep mutlak yang dimaksud adalah sesuatu hal yang sudah ada pada sebuah tanda. Kedua unsur Signifier dan Signified bagaikan dua sisi dari sekeping mata uang atau selembar uang kertas. Contoh petanda adalah, mengartikan sebuah penanda yaitu rambu-rambu lalulintas " $P$ " yang disilang artinya dilarang parkir.

Tujuan penelitian ini adalah mendeskripsikan analisis sosok Laisa dengan kajian semiotik Ferdinand De Saussure pada novel Dia Adalah Kakakku karya Tere Lieye. Dimana peneliti mendeskripsikan sosok Laisa berdasarkan karakter tokoh yang baik hati, mandiri, rela berkorban, kuat, penyayang dan juga sabar, menggunakan kajian semiotik Ferdinand De Saussure yang memaknai berdasarkan penanda dan petanda, untuk memudahkan penelitian peneliti memakai pembacaan Heuristik dan Hermeneutik untuk memudahkan dalam mendeskripsikan makna tersebut, yang mana Riffaterre (Lantowa, Marahayu, \& Khairussibyan, 2017, p. 9) menyatakan pembaca heuristik merupakan tahap pembacaan pertama yang harus dilewati oleh setiap pembaca. Tahap pembacaan yang bergerak dari awal ke akhir teks, dari atas kebawah halaman, dan 
mengikuti pembentangan stigmatik. Pada tahap pembacaan heuristik ini, pembaca masih mengalami berbagai hambatan dan proses pemaknaan sehingga hambatan tersebut harus dilampaui dengan melanjutkan bacaan pada tahap kedua. Pembacaan tahap kedua disebut pembacaan hermeneutik (retroaktif). Pada tahap pembacaan retroaktif ini, pembaca melibatkan kompetensi kesusastraan yakni familiaritas pembaca dengan sistem deskriptif, tema-tema, mitologi-mitologi masyarakat, dan terutama sekali dengan teks-teks lain. Pada tahap ini pembaca menyimak teks, mengingat apa yang telah dibacanya melalui tahap pertama, dan memodifikasi pemahaman tersebut berdasarkan apa yang dipahami dalam tahap pembacaan kedua.

\section{METODE PENELITIAN}

Secara teoretis pendekatan yang digunakan pada penelitian ini adalah pendekatan semiotik yang didasarkan pada model Ferdinand De Saussure. Pendekatan ini menggunakan penanda dan petanda sebagai acuannya. Pendekatan ini disesuaikan dengan pengkajian penelitian di dalam rumusan masalah dan fokus masalah yang telah dibuat oleh peneliti yaitu mendeskripsikan bentuk makna semiotik pada novel karya Tere Liye yang berjudul Dia Adalah Kakakku.

Data di dalam konteks penelitian dapat berupa kata-kata, kalimat ataupun situasi dan kondisi nyata yang terkait dengan penelitian yang dilakukan. Data yang digunakan dalam penelitian ini adalah kata frasa, kalimat yang mengandung penanda dan petanda oleh sosok kak Laisa pada novel Dia Adalah Kakakku karya Tere Liye.

Adapun sumber data dalam penelitian ini adalah novel Dia Adalah Kakakku karya Tere Liye, cetakan pertama Oktober 2018 , dengan jumlah halaman iv +394 halaman, terdiri dari 44 subbab, terbitan Republika Penerbit, Jakarta.
Penelitian ini menggunakan teknik pengumpulan data melalui teknik simak, dan teknik mencatat untuk memperoleh data dilakukan dengan menyimak penggunaan data. Langkah-langkah pengumpulan data yang dilakukan dalam penelitian ini yaitu, melakukan menyimak (simak) setiap baris kata pada novel dengan cermat. Selanjutnya, teknik mencatat yang dilakukan setelah teknik menyimak adalah dengan mencatat katakata yang menunjukkan penanda dan petanda di dalam novel karya Tere Liye yang terkait dengan sosok kakak Laisa.

Peneliti juga menggunakan instrumen bantuan dalam penelitian ini. peneliti sendiri dibantu dengan alat bantu yang digunakan oleh peneliti yaitu berupa buku catatan, laptop dan alat tulis serta kartu data. Penelitian ini menggunakan kartu data untuk pengkodean data.

Tabel 1 Kartu Data

\begin{tabular}{|c|c|c|c|c|c|c|c|c|c|c|}
\hline \multirow[b]{2}{*}{$\begin{array}{l}\mathbf{N} \\
\mathbf{o}\end{array}$} & \multicolumn{6}{|c|}{ Penokohan } & \multirow{2}{*}{$\begin{array}{l}\text { Ko } \\
\text { de }\end{array}$} & \multirow[b]{2}{*}{$\begin{array}{c}\text { Dat } \\
\mathbf{a}\end{array}$} & \multicolumn{2}{|c|}{ Tanda } \\
\hline & $\begin{array}{l}\mathbf{B} \\
\mathbf{K} \\
\end{array}$ & $\begin{array}{l}\mathbf{R} \\
\mathbf{B}\end{array}$ & $\begin{array}{l}\mathbf{K} \\
\mathbf{T} \\
\end{array}$ & $\begin{array}{l}\text { M } \\
\mathbf{D}\end{array}$ & $\begin{array}{l}\mathbf{S} \\
\mathbf{B} \\
\end{array}$ & $\begin{array}{l}\mathbf{K} \\
\mathbf{S}\end{array}$ & & & $\begin{array}{c}\text { Penan } \\
\text { da }\end{array}$ & $\begin{array}{c}\text { Petan } \\
\text { da }\end{array}$ \\
\hline & & & & & & & & & & \\
\hline & & & & & & & & & & \\
\hline
\end{tabular}

Keterangan:

DAK/SK/ : Dia Adalah Kakakku/Sosok

BK : Baik

RB : Rela berkorban

KT : Kuat

MD : Mandiri

SB : Sabar

KSS : Kasih Sayang

Peneliti harus mengecek kembali kebenaran atau keabsahannya dari data yang sudah didapatkan. Pengecekkan kembali berguna sebagai penjelasan analisis yang disesuaikan dengan rumusan masalah dalam penelitian. Adapun keabsahan data dalam penelitian ini yaitu ketekunan/keajengan dan pemeriksaan teman sejawat yang mana peneliti menggunakan Dini Nurul Fahriah untuk dapat memberikan masukan, kritik, dan saran pada penelitian yang akan diteliti, yaitu menganalisis sosok Laisa dengan kajian semiotk Ferdinand De Saussure 
pada novel Tere Liye Dia Adalah Kakakku.

Peneliti menganalisis data yang telah didapatkan. Untuk menafsirkan penanda dan petanda dalam novel Tere Liye. Peneliti menggunakan teknik dengan pembacaan heuristik dan hermeneutik atau retroaktif Riffaterre

\section{HASIL DAN PEMBAHASAN Hasil}

Berdasarkan penelitian yang dilakukan, ditemukan hasil yang akan disajikan di dalam bab ini. pada bab ini peneliti menganalisis karya sastra dengan aspek semiotik model Ferdinand De Saussure yang digunakan untuk mendeskripsikan sosok kakak yang terkandung dalam novel Dia Adalah kakakku karya Tere Liye. Pada penelitian ini akan disajikan dalam bentuk penjelasan. Penjelasan dilakukan dengan mengelompokkan tanda yang terdiri atas penanda dan petanda yang berkaitan dengan sosok Laisa.

Pada penelitian ini ditemukannya sosok Laisa yang merupakan sosok seorang kakak pada novel tersebut. dan pada penelitian ini juga di temukan bagaimana sosok Laisa (kakak) yang terkandung dalam dalam novel Dia Adalah kakakku karya Tere Liye secara semiotika berdasarkan model Saussure yakni penanda dan petanda. Terdapat 33 tanda sosok kakak yang ada dalam novel Dia Adalah kakakku karya Tere Liye, yakni; 5 tanda sosok kakak yang baik, 11 tanda rela berkorban, 8 tanda sosok kasih sayang seorang kakak, 1 tanda sosok mandiri, 3 tanda sosok kakak yang kuat,dan 4 tanda sosok kakak yang sabar.

\section{Pembahasan}

Setiap penanda yang berkaitan dengan sosok kakak yang terdapat di dalam novel Dia Adalah kakakku dengan petandanya sebagai pemaknaan dari penanda tersebut. adapun pembahasan hasil penelitian secara keseluruhan berdasarkan tanda sosok kakak ditemukan data tersebut yakni sebagai berikut.

\section{Baik Hati}

Pada pembahasan ini menceritakan sosok Laisa yang baik hati terhadap keluara, kerabat dan semua yang ada di lingkungan sekitarnya. Sikap dimana seseorang begitu ringan dan gampang melakukan hal-hal yang baik, yang menyenangkan dan bermanfaat bagi orang lain. Ada pun tanda sosok baik hati yang ditemukan pada novel Dia Adalah Kakakku karya Tere Liye berjumlah 9 data, yakni sebagai berikut.

\section{(DAK/SK/BK/06)}

Dalimunte menelan ludah Tertunduk. Sia-sia. Idenya akan mubazir. Tidak ada yang menganggapnya serius. Persis seperti selama ini, penduduk kampung seolah sudah pasrah dengan takdir cadas lima meter itu. Mereka toh dulu sudah berkali-kali membuat kincir air raksasa, dan tidak ada hasilnya. Dalimunte perlahan kertaskertas. Tertunduk, menelan ludah. "Tentu saja kincir-kincir itu bekerja!" Seseorang tiba-tiba berseru. Berseru dengan suara lantang sekali. Membuat dengung lebah terdiam. Seketika. Dalimunte menoleh. Gerakan tangannya terhenti. Ia kenal sekali intonasi suara itu. Kak Laisa! Kak Laisa sudah berdiri dari duduknya. "Kita bisa melakukannya. Apa susahnya membuat kincir-kincir itu. Jika Dalimunti bisa membuat dua dengan bamboo seadanya, kita bisa membuatnya yang lebih bagus, lebih kokoh." Kak Laisa berseru, melangkah ke depan.

Pada data DAK/SK/06 dapat di deskripsikan menggunakan pembacaan heuristik, dimana pembacaan ini dilakukan berdasarkan struktur kebahasaannya, yaitu sebagai berikut: Dalimunte menelan ludah (air liur). Tertunduk. Sia-sia 
(percuma). Idenya akan mubazir (tidak berguna). Tidak ada yang menganggapnya (memandangnya) serius (sungguh-sungguh). Persis (sama) seperti selama ini, penduduk kampung seolah sudah pasrah (menyerah) dengan takdir cadas (lapisan tanah keras) lima meter itu. Mereka toh dulu (waktu yang lampau) sudah berkali-kali membuat kincir air raksasa (sangat besar), dan tidak ada hasilnya. Dalimunte perlahan merapikan kertas-kertas. Tertunduk, menelan ludah (air liur).“ "Tentu saja kincir-kincir itu bekerja!" Seseorang tiba-tiba berseru. Berseru (bersuara nyaring) dengan suara lantang (jelas dan nyaring) sekali. Membuat dengung (suara) lebah terdiam. Seketika. Dalimunte menoleh. Gerakan tangannya terhenti. Ia kenal sekali intonasi (laju kalimat) suara itu. Kak Laisa! Kak Laisa sudah berdiri dari duduknya. "Kita bisa melakukannya. Apa susahnya membuat kincir-kincir itu. Jika Dalimunti bisa membuat dua dengan bamboo (tumbuhan) seadanya, kita bisa membuatnya yang lebih bagus, lebih kokoh (kuat)." Kak Laisa berseru, melangkah (maju) ke depan.

Pembacaan hermeneutik merupakan pembacaan yang dilakukan berdasarkan konvensi sastranya. Data DAK/SK/06 dapat dimaknai secara rinci menggunakan hermeneutik pada kalimat "kita bisa melakukannya. Apa susahnya membuat kincir-kincir itu. Jika Dalimunti bisa membuat dua dengan bamboo seadanya, kita bisa membuatnya yang lebih bagus, lebih kokoh." Kak Laisa berseru, melangkah ke depan. Kalimat ini merupakan tanda yang mengacu sebagai penanda di dalam data DAK/SK/06 yang mengandung tanda sosok kakak yang baik.
Petanda dari penanda "kita bisa melakukannya. Apa susahnya membuat kincir-kincir itu. Jika Dalimunti bisa membuat dua dengan bamboo seadanya, kita bisa membuatnya yang lebih bagus, lebih kokoh." Kak Laisa berseru, melangkah ke depan dapat dideskripsikan sebagai tokoh Dalimunte yang kecewa pada saat pertemuan warga di balai kampung karena ide mengenai lima kincir air di sungai untuk mengairi sawah tidak di anggap dan ditolak oleh warga karena penduduk yang sudah pasrah dengan cadas tersebut. namun tibatiba Laisa bersuara dengan sangat lantang yang mengatakan bahwa mereka dapat membangun 5 kincir air tersebut dengan yakinnya Laisa berbicara untuk meyakin kan seluruh warga. Pada kutipan tersebut dapat dimaknai sebagai rasa yang ingin menyenangkan adiknya agar pendapat sang adik dapat diterima seluruh warga dan sekaligus mengajarkan kepada sang adik bagaimana cara berbicara di depan umum dan cara meyakinkan warga.

\section{Rela Berkorban}

Pada pembahasan ini menceritakan bagaimana sosol Laisa yang rela berkorban melakukan apa saja demi melindungi keluarganya dan kehidupan keluarganya. Rela berkorban merupkan sikap yang mencerminkan adanya keikhlasan dalam memberikan sesuatu yang dimiliki orang lain. Ada pun tanda sosok rela berkorban yang ditemukan pada novel Dia Adalah Kakakku karya Tere Liye berjumlah 9 data, yakni sebagai berikut.

\section{(DAK/SK/RB/05)}

"Eh, nanti Yashita boleh sekolah, kan?" Yashita bertanya sekali lagi, ragu-ragu. Ah, kalau ia sekolah, Mamak dan Kak Laisa pastilebih repot lagi mencari uangnya. 
"Sekolah, Yash! Lepas Panen Ladang musim inikau masuk sekolah!" Mamak Lainuri yang menjawab.Beneran? Yashita menyeringai. Matanya membulat. Mamak mengangguk selintas, tetap konsentrasi menganyam. Yashita sudah tersenyum riang. Tadi, kan, Kak Laisa bilang anak lelaki harus sekolah. Kalau anak perempuan? Lihat, Kak Laisa, kan, anak perempuan, makanya ia tidak sekolah. Yashita berpikir pendek. Jadi dipikirkannya sepanjang hari. Ia tidak tahu kalau sebenarnya Kak Laisa yang memutuskan mengalah untuk tidak sekolah agar adikadiknya bisa bersekolah.

Pada data DAK/SK/RB/05 dapat dideskripsikan menggunakan pembacaan heuristik, di mana pembacaan ini dilakukan berdasarkan struktur kebahasaannya, yaitu sebagai berikut: "Eh, nanti Yashita boleh sekolah, kan?" Yashita bertanya sekali lagi, ragu-ragu. Ah, kalau ia (Yashita) sekolah, Mamak dan Kak Laisa pasti lebih repot lagi mencari uangnya. "Sekolah, Yash! Lepas Panen Ladang musim ini kau masuk sekolah!" Mamak Lainuri yang menjawab. Beneran? Yashita menyeringai (tersenyum). Matanya membulat. Mamak mengangguk (mengiakan) selintas, tetap konsentrasi menganyam. Yashita sudah tersenyum riang. Tadi, kan, Kak Laisa bilang anak lelaki harus sekolah. Kalau anak perempuan? Lihat, Kak Laisa, kan, anak perempuan, makanya ia (Laisa) tidak sekolah. Yashita berpikir pendek. Jadi dipikirkannya (Yashita) sepanjang hari. Ia tidak tahu kalau sebenarnya Kak Laisa yang memutuskan mengalah untuk tidak sekolah agar adik-adiknya bisa bersekolah.

Pembacaan merupakan pembacaan yang dilakukan berdasarkan konvensi sastranya. Data DAK/SK/RB/05 dapat dimaknai secara rinci menggunakan hermeneutik pada kalimat Kak Laisa yang memutuskan mengalah untuk tidak sekolah agar adik-adiknya bisa bersekolah Kalimat ini merupakan tanda yang mengacu sebagai penanda di dalam data DAK/SK/RB/05 yang mengandung tanda sosok kakak yang rela berkorban.

Petanda dari penanda Kak Laisa yang memutuskan mengalah untuk tidak sekolah agar adik-adiknya bisa bersekolah. Dapat dideskripsikan sebagai tokoh Yashita yang bertanya kepada mamak apakah Yashita dapat bersekolah karena pada siang hari di sungai Laisa berkata pada Dalimunte bahwa anak lelaki harus bersekolah, sedangkan Laisa anak perempuan tidak bersekolah. Tapi pada kenyataannya anak perempuan juga harus sekolah, hanya saja Laisa tidak bersekolah karena Laisa mengalah terhadap adik-adiknya dan memutuskan berhenti agar adikadiknya dapat terus bersekolah. Kutipan tersebut dapat dimaknai sebagai pengorbanan sang kakak dengan berhenti sekolah dan membantu orang tua mencari uang agar adik-adiknya dapat terus menuntut ilmu.

\section{Sosok Yang Kuat}

Pada pembahasan ini menceritakan bagaimana sosok Laisa yang kuat mampu menahan cobaan dan masalah yang menghampirinya, tidak menyerah, dan terus berdiri setiap kali jatuh tertunduk. Ada pun tanda sosok Laisa yang kuat yang ditemukan pada novel Dia Adalah Kakakku karya Tere Liye berjumlah 2 data, yakni sebagai berikut. 


\section{( DAK/SK/KT/10 )}

Kali ini kalimat Ikanuri benar-benar bak roket yang ditembakkan tiga kali di lubang yang sama. Berderum. Membuat lubang itu menganga lebarlebar, hitam pekat. Laisa terperangah. Sesak. Napasnya sesak seketika. Ya Tuhan, apa yang barusan dikatakan adiknya. Apa ia sungguh tak salah dengar? Laisa gemetar. Tangannya yang mencengkram ranting bergetar, terlepas."Kenapa? Kenapa kau diam? Kau marah aku mengatakan itu, hah?" Ikanuri tanpa rasa iba bertanya bengis. Laisa menelan ludah. Matanya tiba-tiba berair. Ya Allah, aku mohon, jangan pernah,jangan pernah buat aku menangis di depan adik-adikku. Jangan pernah! Itu akan membuat mereka kehilangan teladan. Laisa meremas pahanya kencangkencang. Berusaha mengalihkan rasa sakit dihati kerasa sakit ditubuhnya. "kami tidak akan lagi patuh.... Kau bukan kakak kami. Bukan! Bukan! BUKAN!" Ikanuri berseru amat puas. Berkali-kali.

Pada data DAK/SK/KT/10 dapat dideskripsikan menggunakan pembacaan heuristik, di mana pembacaan ini dilakukan berdasarkan struktur kebahasaannya, yaitu sebagai berikut: Kali ini kalimat Ikanuri benar-benar bak roket yang ditembakkan tiga kali di lubang yang sama. Berderum. Membuat lubang itu menganga lebar-lebar, hitam pekat. Laisa terperangah (terkejut dan terdiam). Sesak. Napasnya (Laisa) sesak seketika. Ya Tuhan, apa yang barusan dikatakan adiknya. Apa ia (Laisa) sungguh tak salah dengar? Laisa gemetar. Tangannya (Laisa) yang mencengkram ranting bergetar, terlepas. "Kenapa? Kenapa kau (Laisa) diam? Kau marah aku (Ikanuri) mengatakan itu, hah?" Ikanuri tanpa rasa iba bertanya bengis. Laisa menelan ludah. Matanya (Laisa) tiba-tiba berair. $Y a$
Allah, aku (Laisa) mohon, jangan pernah,jangan pernah buat aku (Laisa) menangis di depan adikadikku. Jangan pernah! Itu akan membuat mereka (Ikanuri dan Wibisana) kehilangan teladan. Laisa meremas pahanya kencang-kencang. Berusaha mengalihkan rasa sakit dihati kerasa sakit ditubuhnya. "kami (Ikanuri dan Wibisana) tidak akan lagi patuh.... Kau bukan kakak kami (Ikanuri dan Wibisana). Bukan! Bukan! BUKAN!" Ikanuri berseru amat puas. Berkali-kali.

Pembacaan

hermeneutik merupakan pembacaan yang dilakukan berdasarkan konvensi sastranya. Data DAK/SK/KT/10 dapat dimaknai secara rinci menggunakan hermeneutik pada kalimat: Ya Allah, aku mohon, jangan pernah,jangan pernah buat aku menangis di depan adik-adikku. Jangan pernah! Itu akan membuat mereka kehilangan teladan. Kalimat ini merupakan tanda yang mengacu sebagai penanda di dalam data DAK/SK/KT/10 yang mengandung tanda sosok kakak yang kuat dan juga sabar.

Petanda dari penanda Ya Allah, aku mohon, jangan pernah,jangan pernah buat aku menangis di depan adik-adikku. Jangan pernah! Itu akan membuat mereka kehilangan teladan. Dapat dideskripsikan sebagai tokoh Ikanuri dan Wibisana yang tertangkap telah kabur dari kegiatan gotong royong warga dan tertangkap telah mencuri buah manga di ladang, namun Ikanuri dan Wibisana tidak mengakuinya justru karna mereka ketakutan mereka malah mengatangatai kak Laisa, membentak dan menantang Laisa. Laisa yang mendengar perkataan Ikanuri terkejut tidak dapat berbuat apa-apa. Laisa ingin menangis karena ucapan Ikanuri namun Laisa menahannya, laisa tidak ingin Ikanuri dan 
Wibisana melihatnya menangis di depan mereka karena Laisa takut Ikanuri dan Wibi kehilangan panutan dan Laisa hanya terdiam mendengar itu semua. Pada kutipan tersebut dimaknai sebagai usaha sang kakak menahan perih di hatinya mendengar perkataan sang adik kepadanya dengan memindahkan rasa sakit ke paha sang kakak yang sengaja di cengkram dengan kuat agar sang kakak tidak menangis di depan sang adik dengan perkataan mereka.

\section{Sosok Yang Mandiri}

Pada pembahasan ini menceritakan kemandirian Laisa dalam kehidupannya yang merupakan sikap untuk tidak menggantungkan keputusan kepada orang lain. Ada pun tanda sosok Laisa yang mandiri, yang ditemukan pada novel Dia Adalah Kakakku karya Tere Liye berjumlah 1 data, yakni sebagai berikut.

\section{( DAK/SK/MD/23)}

Kak Laisa tidak berubah sedikit pun, persis seperti melihat foto masa lalu. Hanya saja sekarang piguranya terlihat kecoklatan. Umurnya sekarang telah lewat dari empatpuluh tahun, tapi ia masih sama disilplinnya. Terus bekerja keras mengurus kebun, mengurs mamak, mengurus pabrik pengalengan, mengurus sekolah di lembah, mengurus apa saja. Melakukan banyak hal. Masih sama kuatnya. Masih dengan tubuh gemuk tapi gempalnya. Padahal kalau Kak Laisa ingin duduk-duduk santai, tidak masalah. Pabrik itu punya belasan pekerja, warga dari Kampung Atas dan sebrang. Juga turut bekerja di perkebunan beberapa insinyur pertanian lulusan institute pertanian Kota Provinsi.

Pada data DAK/SK/MD/23 dapat dideskripsikan menggunakan pembacaan heuristik, di mana pembacaan ini dilakukan berdasarkan struktur kebahasaannya, yaitu sebagai berikut: Kak Laisa tidak berubah sedikit pun, persis seperti melihat foto masa lalu. Hanya (Laisa) saja sekarang piguranya (gambaran) terlihat kecoklatan. Umurnya (Laisa) sekarang telah lewat dari empat puluh tahun, tapi ia (Laisa) masih sama disilplinnya. Terus bekerja keras mengurus (merawat) kebun, mengurus (merawat) mamak, mengurus pabrik pengalengan, mengurus (merawat) sekolah di lembah, mengurus (merawat) apa saja. Melakukan banyak hal. Masih sama kuatnya. Masih dengan tubuh gemuk tapi gempalnya (padat berisi). Padahal kalau Kak Laisa ingin duduk-duduk santai, tidak masalah. Pabrik itu punya belasan pekerja, warga dari Kampung Atas dan sebrang. Juga turut (ikut) bekerja di perkebunan beberapa insinyur (sarjana) pertanian lulusan institut pertanian Kota Provinsi.

Pembacaan

hermeneutik merupakan pembacaan yang dilakukan berdasarkan konvensi sastranya. Data DAK/SK/MD/23 dapat dimaknai secara rinci menggunakan hermeneutik pada kalimat: Terus bekerja keras mengurus kebun, mengurs mamak, mengurus pabrik pengalengan, mengurus sekolah di lembah, mengurus apa saja.Kalimat ini merupakan tanda yang mengacu sebagai penanda di dalam data DAK/SK/MD/23 yang mengandung tanda sosok kakak yang mandiri.

Petanda dari penanda Terus bekerja keras mengurus kebun, mengurs mamak, mengurus pabrik pengalengan, mengurus sekolah di lembah, mengurus apa saja. Dideskripsikan sebagai tokoh Laisa yang tidak banya berubah pada usianya yang lebih dari 40 tahun, 
hanya kulitnya yang berwarna kecoklatan karena terbakar sinar matahari, masih tetap disiplin dan terus bekerja keras dalam segala hal. Namun walaupun Laisa telah mendapatkan tenaga professional untuk mengurus perkebunan dan pekerjaannya, Laisa lebih memilih untuk terjun langsung turun tangan melakukan pekerjaan tersebut. pada kutipan tersebut dimaknai sebagai usia yang terus bertambah tidak membuat sang kakak untuk bersantai ria, dan walaupun telah tersedia tenaga professional sang kakak tetap melakukan pekerjaannya sendiri.

\section{Sosok Kasih Sayang}

Pada pembahasan ini membahas kasih sayang Laisa terhadap adikadiknya yang mencermikan sikap menghormati, mengayomi, mengasihi, peduli, merawat dan berempati kepada sesame makhluk ciptaa tuhan. Ada pun tanda sosok kasih sayang Laisa, yang ditemukan pada novel Dia Adalah Kakakku karya Tere Liye berjumlah 17 data, yakni sebagai berikut.

\section{( DAK/SK/KS/26)}

Kak Laisa menendang pintu depan. Berdebam. Lantas diikuti oleh tatapan bingung mamak, entah apa yang akan dilakukannya, Kak Laisa sudah berlari menghambur ke tengah derasnya hujan. Angina menderu kencang, masuk ke dalam rumah, mengirimkan bilur-bilur air, membuat perabotan berderak. Kak Laisa berlari sekuat kakinya ke Kampung Atas. Tidak peduli tetes airhujan bagai kerikil batu yang ditembakkan dari atas. Tidak peduli tubuhnya basah kuyup. Tidk peduli malam yang gelap gulita. Dingin membungkus hingga ujung kaki. Musim kemarau begini di malam hari, suhu Lembah Lahambay bisa mencapai delapan derajar Celsius.
Kak Laisa berlarian menaiki lembah. Terpeleset. Sekali. Dua kali. Tidak peduli. Petir menyalak. Guntur menggelegar. Ia ingat. Ia ingat kakakkakak mahasiswa tadi menyebutnyebut soal obat dan dokter. Mereka pasti bisa membantu. Ia harus segera, waktunya terbatas.

Pada data DAK/SK/KS/26 dapat dideskripsikan menggunakan pembacaan heuristik, di mana pembacaan ini dilakukan berdasarkan struktur kebahasaannya, yaitu sebagai berikut: Kak Laisa menendang pintu depan. Berdebam (suara bising). Lantas diikuti oleh tatapan bingung (heran) mamak, entah apa yang akan dilakukannya, Kak Laisa sudah berlari menghambur (terjun) ke tengah derasnya hujan. Anginya menderu (berbunyi) kencang, masuk ke dalam rumah, mengirimkan bilurbilur (rintik) air, membuat perabotan berderak. Kak Laisa berlari sekuat kakinya ke Kampung Atas. Tidak peduli tetes air hujan bagai kerikil (batu kecil) batu yang ditembakkan dari atas. Tidak peduli tubuhnya basah kuyup. Tidak peduli malam yang gelap gulita. Dingin membungkus (menyelimuti) hingga ujung kaki. Musim kemarau begini di malam hari, suhu Lembah Lahambay bisa mencapai delapan derajar Celsius (suhu). Kak Laisa berlarian menaiki lembah. Terpeleset. Sekali. Dua kali. Tidak peduli. Petir menyalak (mengeluarkan bunyi). Guntur menggelegar (berbunyi gemuruh). Ia (Laisa) ingat. Ia (Laisa) ingat kakak-kakak mahasiswa tadi menyebut-nyebut soal obat dan dokter. Mereka pasti bisa membantu. Ia harus segera, waktunya terbatas.

Pembacaan

hermeneutik merupakan pembacaan yang dilakukan berdasarkan konvensi sastranya. Data DAK/SK/KS/26 dapat dimaknai secara rinci menggunakan hermeneutik pada 
kalimat Kak Laisa berlari sekuat kakinya ke Kampung Atas. Kalimat ini merupakan tanda yang mengacu sebagai penanda di dalam data DAK/SK/KS/26 yang mengandung tanda kasih sayang sosok seorang kakak.

Petanda dari penanda Kak Laisa berlari sekuat kakinya ke Kampung Atas. Dideskripsikan sebagai tokoh Laisa yang berlari menerobos hujan dan dinginnya malam menuju kampung atas untuk meminta bantuan mahasiswa KKN sebrang provinsi untuk mengobati Laisa yang sekarat. Laisa meminta bantuan mahasiswa KKN karena mereka pernah menyinggung masalah pengobatan pada saat pertemuan di balai kampung. Laisa menerobos hujan dan dinginnya malam dengan penerangan yang minim hingga membuat laisa terjatuh dan tersandung berkali-kali saat menaiki lereng menuju kampung atas. Namun itu semua tidak di perdulikan oleh Laisa, yang terpenting saat ini ialah ia harus segera membawa kakakkakak mahasiswa itu sebelum terlambat. Dari kutipan tersebut dimaknai sebagai kepedulian dan kasih sayang sang kakak terhadap sang adik, tidak memperdulikan hujan dan dinginnya udara malam sang kakak tetap mencari bantuan demi sang adik.

\section{Sosok Yang Sabar}

Pada pembahasan ini menceritakan kesabaran seorang kakak yang menahan emosi dan keinginan serta bertahan dalam situasi sulit dengan tidak mengeluh. Ada pun tanda sosok Laisa yang sabar, yang ditemukan pada novel Dia Adalah Kakakku karya Tere Liye berjumlah 5 data, yakni sebagai berikut.

\section{( DAK/SK/SB/30)}

"Dia Kakakku." Yashita menjawab ketus, tersinggung dengan tatapan petugas. Meski umurnya baru dua belas tahun, yashita mengerti benar soal beginian. Soal tatapan mata seperti ini. kalimat-kalimat sepeti ini. ia berkali-kali mengalaminya. "Kakakmu? Kalian sungguh berbeda. Ia lebih pendek... Baiklah." Maka Yashita merajuk, berlari keluar ruangan pendaftaran. Melempar formulir pendaftarannya. Tidak. Tidak ada yang boleh menghina kakaknya. Ia tidak akan sekolah di sini. Ia bisa sekolah di mana saja ia mau, tapi bukan di sini. "Yash seharusnya tidak marah. Yash seharusnya terbiasa." KakLaisa duduk di sebelah. Ikut bersandarkan kucing panjang. Menghela napas. Mendekap bahu adiknya.

Pada data DAK/SK/SB/30 dapat dideskripsikan menggunakan pembacaan heuristik, di mana pembacaan ini dilakukan berdasarkan struktur kebahasaannya, yaitu sebagai berikut: "Dia Kakakku." Yashita menjawab ketus (keras), tersinggung (merasa disakiti) dengan tatapan (cara melihat) petugas. Meski umurnya baru dua belas tahun, yashita mengerti benar soal beginian. Soal tatapan (cara melihat) mata seperti ini. kalimat-kalimat sepeti ini. ia berkali-kali mengalaminya (pernah mersakan). "Kakakmu (Laisa)? Kalian sungguh berbeda (tidak sama). Ia (Laisa) lebih pendek... Baiklah." Maka Yashita merajuk (marah), berlari keluar ruangan pendaftaran. Melempar formulir (lembar isian) pendaftarannya. Tidak. Tidak ada yang boleh menghina (menjelek-jelekkan) kakaknya. Ia tidak akan sekolah di sini. Ia bisa sekolah di mana saja ia mau, tapi bukan di sini. "Yash seharusnya tidak marah. Yash seharusnya terbiasa." Kak Laisa duduk di sebelah. Ikut 
bersandarkan (bertompang) kursi panjang. Menghela (menghirup) napas. Mendekap (memeluk) bahu adiknya.

Pembacaan

hermeneutik merupakan pembacaan yang dilakukan berdasarkan konvensi sastranya. Data DAK/SK/SB/30 dapat dimaknai secara rinci menggunakan hermeneutik pada kalimat: "Yash seharusnya tidak marah. Yash seharusnya terbiasa." Kalimat ini merupakan tanda yang mengacu sebagai penanda di dalam data DAK/SK/SB/30 yang mengandung tanda sosok seorang kakak yang sabar.

Petanda dari penanda "Yash seharusnya tidak marah. Yash seharusnya terbiasa"'Dideskripsikan sebagai tokoh Yashita yang kecewa terhadap petugas pendaftaran sekolah tempat dimana Yashita akan bersekolah. Siang itu Yashita mendaftar di salah satu sekolah yang pernah di masuki oleh kakak-kakak Yashita sebelumnya namun Yashita kecewa karena petugas mengatakan dan tidak percaya bahwa Laisa adalah kakak Yashita hingga membawa fisik. Hal tersebut membuat Yashita marah dan pergi dari tempat tersebut, namun Laisa mendatangi Yashita yang sedang kesal dan memintanya untuk sabardan tidak marah, laisa mengajarkan pada Yashita bahwa ia harus bersabar seperti kakakkakaknya sebelumnya, berusaha untuk tidak mendengarkan omongan orang mengenai dirinya. Pada kutipan tersebut di maknai sebagai kesabaran sang kakak akan perkataan orang yang menyayat hati dan belajar untuk terbiasa menahan diri dari perkataan orang lain terhadapnya.

\section{KESIMPULAN}

Berdasarkan hasil penelitian dan pembahasan terhadap Sosok Laisa pada Novel Dia Adalah Kakakku Karya Tere, peneliti dapat menarik kesimpulan bahwa dengan adanya fokus penelitian dan rumusan masalah yang telah ditentukan. Peneliti menemukan penanda dan petanda dalam novel Dia Adalah Kakakku Karya Tere Liye. Peneliti menemukan 33 tanda yang menjadi bentuk tanda sosok Laisa.

\section{DAFTAR PUSTAKA}

Lantowa, J., Marahayu, N. M., \& Khairussibyan, M. (2017). Semiotika Teori, Metode, dan Penerapannya Dalam Penelitian Sastra. Yogyakarta: Deepublish.

Liye, T. (2018). Dia Adalah Kakakku. Jakarta: Republika Penerbit.

Mahsun. (2014). Metode Penelitian Bahasa: Tahapan Strategi, Metode dan Strateginya (Rev.ed.). Jakarta: Rajawali Pers.

Maslikatin, T., Mariyati, S., \& Armis, M. (2015). Representasi Tokoh Lisa Dalam Novel Bunda Lisa Karya Jombang Santani Khairen: Kajian Psikologi Wanita. Publika Budaya, 33.

Moleong. (2017). Metodologi Penelitian kualitatif. Bandung: PT Remaja Rosdakarya.

Nurgiyantoro, B. (2015). Teori Pengkajian Fiksi. Yogjakarta: Gajah Mada University Press. 